\title{
O CUIDAR DA CRIANÇA E DA FAMÍLIA: DAS REFLEXÕES TEÓRICAS À SUA APLICAÇÃO NA PRÁTICA PROFISSIONAL DO COTIDIANO
}

\author{
TAKING CARE OF THE CHILD AND THE FAMILY: OF THE THEORETICALREFLECTIONS TO \\ ITS APPLICATION IN THE PRACTICAL PROFESSIONAL OF THE DAILY ONE
}

\author{
EL CUIDADO DEL NIÑO Y DE LA FAMILIA: LAS REFLEXIONES TEÓRICAS Y SU \\ APLICACIÓN EN LA PRÁCTICA DEL PROFESSIONALEN SU COTIDIANO
}

Tereza Yoshiko Kakehashi* Conceição Vieira da Silva**

\begin{abstract}
RESUMO: Trata-se de uma reflexão sobre as possibilidades de aplicação do referencial de cuidado do filósofo americano Mayeroff na assistência de enfermagem em Neonatologia e Pediatria, tendo como foco a família. Considerando que o cuidar, na acepção de Mayeroff significa ajudar o outro a crescer, as autoras abordam as diversas situações que ocorrem no cotidiano dos profissionais que assistem o neonato e a criança, fazendo reflexões de como podem ser vivenciados os conceitos de Mayeroff. Nesse cuidado, cada família, embora necessitando de atenção e apoio da equipe assistencial, é vista como parceira no cuidado à criança e neonato, tendo o seu saber, e a maneira peculiar de cada uma. 0 respeito, a honestidade e a manutenção da dignidade como requisitos fundamentais na relação entre equipe e família. Conclui que a instituição deve respeitar e valorizar a expressão da marca pessoal do profissional neste cuidado humanizado.
\end{abstract}

DESCRITORES: Cuidados de enfermagem; Enfermagem; Família; Recém-nascido; Criança.

\section{INTRODUÇÃO}

Como enfermeiras pediatras, percebemos no decorrer de nossa experiência profissional, que a internação de uma criança acarreta transtornos não só para a própria criança, mas também para a família como um todo. Funcionando como uma célula, na qual todos os componentes são interdependentes, a doença de um membro, demanda a mudança de rotina de todos os membros da família, e em muitas ocasiões, a mudança de papéis. Considerando a dependência que a criança apresenta em relação à família, não só no que se refere aos cuidados necessários para a recuperação e manutenção de sua saúde, como também em relação aos aspectos psico-emocionais, é de suma importância que o plano de assistência à criança inclua seus pais e/ou outros familiares. Assim, a evolução da assistência pediátrica hospitalar após confinar a criança sem a possibilidade da presença contínua dos familiares ao seu lado, passou pela primeira transformação ao liberar a visita de seus pais, em seguida instituiu a permanência ou hospitalização conjunta. Por outro lado, a presença constante dos familiares no ambiente do cuidado, exigiu também dos membros da equipe de assistência, novas habilidades, no que se refere ao estabelecimento de relações interpessoais com os mesmos, de modo a possibilitá-los a otimizar a assistência à criança, como também no sentido de capacitá-los ao auto-cuidado para que a experiência hospitalar seja por eles considerado não só um momento de sofrimento, mas também de crescimento pessoal e fortalecimento do vínculo com a criança. É necessário lembrar, que a família como grupo primário de socialização, é a referência para a criança, de sua relação com o mundo: a maneira como ela é cuidada por sua família será a base pela qual relacionará com as pessoas que encontrarão pelo mundo.

\footnotetext{
* Enfermeira. Doutora em Enfermagem. Professora da Universidade do ABC.

** Enfermeira. Doutora em Enfermagem. Professora da Universidade Federal de São Paulo.
} 


\section{A ENFERMAGEM E O CUIDAR}

Desde que entramos na escola de enfermagem, aprendemos que Enfermagem é a arte de cuidar do indivíduo, cuidar esse, inicialmente entendido como sinônimo dos procedimentos técnicos, cuidado com o ambiente e atividades educativas, individuais ou coletivas que enfocavam sobretudo, transmitir informações ligadas aos cuidados com a saúde. $\mathrm{Na}$ fase inicial de sua profissionalização, carecia à Enfermagem um corpo de conhecimento próprio que possibilitasse uma reflexão teorico-filosófica mais aprofundada para poder, por sua vez, produzir um referencial teórico que proporcionasse maior embasamento a uma prática específica capaz de tirar a profissão do status de uma atividade subsidiária da medicina. Aos poucos, o progresso se fez notar, principalmente, a partir da década de 70, quando várias enfermeiras começaram a desenvolver as Teorias de Enfermagem. De início, tomaram emprestados os referenciais de outras áreas, porém, podia-se notar que eles não se restringiram mais àquelas áreas das ciências biológicas nas quais tradicionalmente a Enfermagem se apoiou. Expandiu também para várias áreas das ciências humanas. Podemos citar os esforços da Madeleine Leininger (1978) com a sua Teoria Transcultural do Cuidado, da J ane Watson (1985), com sua Teoria Transpessoal do Cuidado Humano, e de várias outras que resultaram na criação da Associação Internacional para o Cuidado Humano (AICH) em 1978. Seus objetivos, segundo Waldow (1992), incluem:

- Identificar as principais dimensões filosóficas, epistemológicas e profissionais do cuidar e do cuidado para desenvolver e aprimorar o corpo de conhecimento que constitui a enfermagem e ajudar outras disciplinas a usar conhecimento de cuidar e cuidado em relações humanas;

- Esclarecer a natureza, extensão e funções do cuidar e do cuidado e seus relacionamentos com a Enfermagem;

- Identificar os principais componentes, processos e padrões de cuidar e do cuidado em relação à Enfermagem;

- Estimular pesquisas e estudos sobre cuidar e cuidado e compartilhar achados de pesquisa e estudos entre enfermeiras internacionalmente;

- Compartilhar conhecimento através de publicações e encontros.

Recentemente, Boykin e Schoenhofer desenvolveram o currículo de enfermagem, baseado no cuidar/ cuidado humano, tendo o filósofo americano Mayeroff como referencial teórico (Boykin; Schoenhofer, 1993; Boykin, 1994).

No Brasil, o estudo sobre o cuidar/cuidado é mais recente, tendo sido introduzido por Neves-Arruda, Dias e Silva (1993), Patrício (1992; 1993), Silva (1993) e Waldow (1992; 1993). Alguns destes estudos fundamentam-se na Teoria de Cuidado do Mayeroff.

Para Mayeroff, 1971, a essência do cuidar está em ajudar o outro a crescer e se realizar. Neste processo, o cuidar caracteriza-se por estar com a pessoa, no mundo dessa pessoa que é merecedora de cuidado. Envolve desenvolvimento, amizade e principalmente a habilidade de fazer o outro feliz. Deve-se compreender que 0 homem vive o significado da própria vida, e que quando cuida, ele está também, sendo cuidado. Na relação euoutro, o outro precisa de mim para crescer e eu preciso dele para crescer, no sentido de poder atender as necessidades, numa relação que se baseia na confiança e não no uso do poder, reconhecendo suas necessidades e direitos, e fazê-lo tornar-se responsável pela sua vida. Devo ser responsiva à sua necessidade de crescimento (auto-cuidado), no sentido de estimular a busca em direção à completude como ser humano. Cuidar do outro, portanto, é a antítese de manipulação para atender o seu próprio prazer (do cuidador).

Os principais ingredientes do cuidar, para Mayeroff (1971), descritos a seguir, são: conhecimento, ritmos alternados, paciência, honestidade, confiança, humildade, esperança e coragem.

\section{CONHECIMENTO}

O cuidar implica na capacidade de entender as necessidades do outro e ser capaz de responder adequadamente a elas. Não basta apenas as boas intenções pois, dificuldades e obstáculos são inevitáveis no processo. Implica em conhecer o outro, quais suas necessidades e como atendê-las para ajudá-lo a crescer. Para tanto, é necessário que o profissional reflita sobre o seu conceito de conhecimento, e evitar restringi-lo apenas àquilo que pode ser verbalizado (conhecimento explícito). Existe também o conhecimento implícito que 
abrange aquele tipo de conhecimento que nem sempre pode ser verbalizado, mas que se o profissional for sensível, pode constituir uma fonte valiosa de comunicação.

\section{RITMOS ALTERNADOS}

Estes constituem movimentos de experiências vivenciadas em diferentes momentos da vida. Ao cuidar de uma pessoa, devo ser capaz de considerar o seu passado, e ser capaz de agir de acordo com as circunstâncias do momento. Devo estar consciente de que um mesmo fato pode produzir efeitos diferentes, dependendo do contexto (Mayeroff, 1971).

\section{PACIÊNCIA}

Consiste, segundo Mayeroff (1971), em permitir ao outro que cresça em seu ritmo e de sua própria maneira. Não se trata de uma espera passiva, mas participativa, uma presença, na qual nos colocamos por inteiro. Mas, ao mesmo tempo, é preciso dar ao outro, o espaço para pensar e sentir, ampliando dessa maneira, o sentido de sua vida. Para ser paciente com o outro, o profissional deve aprender a ser paciente consigo mesmo e também ser capaz de se cuidar.

\section{HONESTIDADE}

A honestidade no cuidar deve ter uma característica positiva e não apenas de não mentir ou depreciar outros. Significa confrontar ativamente, ser franco e aberto. Em relação ao outro, é enxergá-lo como ele é e não como gostaríamos que fosse e tampouco como sentimos que deveria ser. Consiste também em nos colocarmos exatamente como somos, é a pré-condição necessária para podermos estar inteiramente para o outro. Isto seria impossível se estivéssemos mais preocupados em como o outro nos julga. Devemos admitir as possibilidades de erro e aprender com eles. Ser genuíno no cuidar, implica na coerência entre o que se fala e faz, e entre o que se fala e sente.

\section{CONFIANÇA}

Envolve confiar na capacidade do outro de crescer em seu próprio ritmo e de sua maneira própria. Significa torná-lo independente, com liberdade e autonomia. A dependência mórbida é incompatível com a confiança. Implica deixar experimentar o desconhecido, apesar dos seus perigos. É preciso também confiar na minha capacidade de cuidarmos e sermos capazes de nos cuidar. A preocupação contínua se as nossas ações estão corretas, indica a falta de confiança em nós mesmos e nos deixa indiferentes às necessidades do outro (Mayeroff, 1971).

\section{HUMILDADE}

O cuidar envolve a aprendizagem contínua sobre o outro. 0 homem que cuida é genuinamente humilde e está sempre disposto a aprender mais sobre o cuidado e sobre si mesmo, incluindo aprender através da pessoa cuidada. Nenhuma fonte de aprendizagem é desperdiçada, nem mesmo os seus próprios erros. A atitude de não ter mais nada a aprender é incompatível com o cuidar. Assim, o homem consegue um novo olhar sobre as suas experiências anteriores e consegue adaptar os princípios à cada nova situação, evitando a repetição mecânica dos princípios (Mayeroff, 1971).

\section{ESPERANÇA}

A esperança de que o outro cresça com o nosso cuidado, não indica, na opinião de Mayeroff (1971), uma insuficiência no presente, em comparação ao futuro esperado, é antes, uma expressão da plenitude do 
presente, um presente vivo com o senso do possível. Não se trata de uma espera passiva de que algo aconteça, mas uma busca que se mobiliza no presente. Assim, um dos aspectos da confiança é a coragem de assumir os riscos.

\section{CORAGEM}

Consiste em enfrentar o desconhecido no processo de cuidar, no qual se perde a segurança da familiaridade e não tenho nenhuma garantia de quem o outro será ou quem seremos nós - deve estar baseada tão somente na confiança no outro e na minha capacidade de cuidar (Mayeroff, 1971).

Veremos, a seguir, como alguns destes conceitos podem ser utilizados na prática cotidiana de enfermagem neonatológica e pediátrica, junto ao ser que necessita de cuidados diretos e aqueles que sofrem por ele - a família.

\section{VIVENCIANDO O CUIDAR NA ASSISTÊNCIA DE ENFERMAGEM NEONATOLÓGICA E PEDIÁTRICA, COM FOCO NA FAMÍLIA}

O cuidar em enfermagem neonatológica e pediátrica deve partir do princípio de que tanto a criança (RN), como a mãe e a família constituem o núcleo de atenção da enfermagem. Isto implica na compreensão de que a criança está inserida numa família com uma história própria, que por sua vez, pertence a um grupo social com todas as determinações histórico-culturais. Assim, mesmo a criança que acaba de nascer, traz consigo toda a carga de expectativas geradas no seio da família e ocupa um lugar específico no interior desse grupo.

Considerando a total dependência do recém-nascido em relação aos adultos, a atenção da enfermeira no cuidar/cuidado e ajudar o outro a crescer, deve estar voltada à família, e mais especificamente aos pais. Assim sendo, passaremos a analisar algumas ocorrências comuns da prática de enfermagem neonatológica e pediátrica, para fazer uma reflexão sobre como os conceitos de Mayeroff (1971) podem ser vivenciados nesta situação.

E m primeiro lugar, para poder ajudar o outro a crescer, deve-se aceitar os familiares como parceiros na assistência à criança, e portanto, deve-se considerar as suas capacidades de atender as necessidades da criança. 0 fato dos familiares não possuírem a mesma formação profissional que a nossa, não nos autoriza a pensar que os mesmos sejam incapazes de perceber as necessidades da criança e de atendê-las. Ao mesmo tempo, os familiares são em geral, atentos observadores de tudo que acontece com a criança e certamente elaboram suas conclusões e fazem os seus julgamentos. Valorizar a capacidade dos familiares na assistência aos seus filhos, constitui uma estratégia de conservar a sua auto-estima e dignidade. Segundo Shotton; Seedhouse (1998), a dignidade pode ser definida como a possibilidade das pessoas exercerem a sua capacidade e que nenhuma pessoa que não tivesse experimentado uma situação que atentasse contra a sua dignidade, é capaz de avaliar o que seja a sua falta. A comunicação eficaz, então se faz fundamental no sentido de que a família seja corretamente informada. Tudo que fica no ar, mal compreendido, cria a possibilidade de desenvolver fantasias, que por vezes são vivenciadas mais intensamente do que a própria realidade, impossibilitando dessa maneira, a compreensão da real situação que estão vivenciando. Os requisitos básicos nesta comunicação, conforme Mayeroff (1971), são a honestidade e a humildade. 0 respeito à família, implica em não minimizar quaisquer de suas preocupações, por mais banais que nos pareçam ser, pois, acostumados às rotinas, às vezes perdemos a nossa sensibilidade e a nossa capacidade crítica. Aprenderemos muito, se conseguirmos escutar com atenção o relato da observação feito pela família e valorizá-la.

Não basta dizermos que estamos disponíveis para escutar os pais, uma vez que isto, não seja verdade, demonstraremos nas nossas expressões corporais, tais como o andar mais apressado, executar algumas tarefas enquanto conversamos com os familiares, o desassossego e o contínuo olhar para outros espaços. Para verdadeiramente nos colocarmos na presença da família, é preciso também providenciar um ambiente propício para que a mesma se sinta à vontade para expor suas preocupações e dúvidas. Na atenção que dispensamos, não devemos nos limitar às informações sobre rotinas, mas mantermos abertos para qualquer possibilidade de atendimento individualizado às necessidades da família naquele momento. As rotinas 
estabelecidas tem o seu valor no sentido de ajudar a otimizar o trabalho, mas se as mesmas se tornam rígidas impedindo a manifestação da expressão pessoal seja do cuidador, seja da pessoa cuidada, certamente não serão úteis para as perspectivas deste cuidar, pois anula uma das condições primordiais para o crescimento humano que é a liberdade e autonomia. Assim, permitir à família e aos cuidadores, no ambiente hospitalar a expressão da individualidade, que não afete os requisitos gerais de segurança e os relacionados às infecções, tais como permitir que tragam a roupa da criança, ou um brinquedo lavável, ajuda a imprimir individualidade à criança: ela se torna, aos olhos dos familiares, diferenciada das demais, além de Ihes proporcionar a sensação de estar fazendo algo por ela.

Outra situação que implica na falta de respeito ao outro, freqüentemente acontece na realização da anamnese. Em um hospital universitário complexo, há a participação de inúmeros profissionais na assistência e cada qual realiza a sua anamnese, repetindo incontáveis vezes as mesmas perguntas, levantando por vezes, dados que sequer serão utilizados na assistência. Em nome da suposta assistência integral, verificamos o autêntico retalhamento da criança e da família. Parece haver nesta atitude, a falta de respeito em relação à criança e aos familiares, e também a desconfiança nas informações colhidas por outros profissionais.

Conquistar a confiança dos familiares implica em proporcionar a sensação de segurança e continuidade no cuidado. Nada será pior para eles do que encontrar a cada dia, funcionários diferentes cuidando de seu filho, funcionários estes que por sua vez, os chamam de pai e mãe, negando desta maneira suas condições de pessoa: homem ou mulher com suas histórias de vida, despindo-os de qualquer traço de individualidade, num processo que Goffman (1961) chama de Mortificação ou mutilação do eu. Isto transmite insegurança e desconfiança quanto ao cuidado da criança e impede a formação do vínculo com as pessoas da equipe, pois ele não é possível com pessoas a quem negamos a sua humanidade. Estaria assim caracterizada uma situação de perda devastadora da dignidade, conforme assinalam Shooton; Seedhouse (1998). Programas de saúde bem elaborados podem resultar em completo fracasso se este aspecto não for considerado.

É necessário reconhecer o esforço desenvolvido pelos familiares, reconhecer os seus progressos e estimulá-los. Não se impacientar com as perguntas repetitivas, pois estas, principalmente se a criança está grave, significa muito mais a procura por respostas diferentes que de alguma maneira venham a atender os seus desejos, do que propriamente a falta de confiança em suas repostas.

o que família espera dos profissionais é, além de resolver o problema clínico da criança, ser tratada com atenção e respeito. Não se trata de passar uma enorme quantidade de orientações, mas a partir daquilo que eles já conhecem, ajudar na busca de soluções; não se trata de evitar os erros, mas o direito de crescer através e apesar deles, sem por isso ser julgada e rotulada pejorativamente, não se trata de lhe evitar sofrimentos, que por vezes são inerentes à situação e à condição humana, mas de proporcionar a poio nas situações de dor, para que possa mobilizar adequadamente sua energia; não se trata de sentir piedade, mas de nos mostrarmos solidários, enfim, de preservar a sua dignidade mesmo em condições adversas, como um ser humano com direitos à esperança de crescer em seu próprio ritmo e viver uma vida plena de significados.

\section{CONSIDERAÇÕES FINAIS}

Partindo-se do princípio de que a relação de cuidar é antes de tudo, uma relação interpessoal que se estabelece entre o agente cuidador e a pessoa cuidada, não há como negar que o profissional imprima a sua marca pessoal nesta relação. Devemos considerar que esta possibilidade de expressão pessoal na relação de cuidar é a manifestação de autonomia do profissional e deve merecer da instituição, o cuidado para assegurar a sua livre expressão, bem como de preservá-la. No entanto, a responsabilidade da instituição não está em apenas apoiar as manifestações individuais dos profissionais, como também, em estabelecer a filosofia de atendimento e de cuidado com seus profissionais de modo a assegurar a cadeia da real qualidade do cuidado. Considerando a família uma das instâncias solidárias de apoio ao indivíduo, que ainda resta na nossa sociedade, principalmente em sua fase de crescimento e desenvolvimento, e agora reforçada pelas mudanças observadas na área da saúde, que têm como uma das mais fortes marcas, a desinternação hospitalar com o incremento dos serviços de assistência domiciliária (home care), a compreensão da dinâmica familiar frente ao processo saúde-doença, é fundamental para se implementar a capacitação da família para o auto-cuidado consciente, base da verdadeira promoção humana. 
ABSTRACT: It's a reflection on the possibilities of application of the referencial of care of the American philosopher Mayeroff in the assistance fo nursing in Neonatology and Pediatric Care, having as focus the family. Considering that taking care of, in the meaning of Mayeroff in means to help the other to grow, the authors approach the diverse situations that occur in the daily one of the professionals who attend to the neonato and the child, making reflections of as the concepts of Mayeroff can be lived deeply. In this care, each family, even so needing attention and bracket the assistencial team, is seen as partner in the care to the child and neonato, having its to know, and the peculiar way of each one. The respect, the honesty and the basic maintenance of the dignity as requisite in the relation between team and family. It concludes that the institution must respect and value the expression of the personal mark of the professional in the humanistic care.

KEY WORDS: Nursing care; Nursing; F amily; Infant newborn; Child.

RESUMEN: Es una reflexión sobre las posibilidades de aplicación del referencial del cuidado del filósofo americano Mayeroff en la ayuda del cuidado en Neonetologia y Pediatria, teniendo como foco la familia. Considerando que tomar cuidado, en significado Mayeroff és ayudar uno a otro para crescer, las autoras abordam diversas situaciones que puedem ocurrir en el cotidiano de los professionales quien atenden el neonato y niño, haciendo reflexiones a medida que los conceptos de Mayeroff pueden ser vividos. En este cuidado, cada familia, necesita de la atención y apoyo del equipo assistencial, se ve como socio en el cuidado al niño y al neonato, teniendo su saber, y la manera peculiar de cada uno. El respecto, la honradez y el mantenimiento básico de la dignidad como requisito en la relación entre el equipo y la familia. Concluye que la institución debe respectar y valorar la expresión de la marca personal del profesional en el cuidado humanizado.

PALABRAS CLAVE: Atención de enfermeria; Enfermeria; Familia; Recien nacido; Niño.

\section{REFERÊNCIAS}

1 BOYKIN, A.; SCHOENHOFER, S. Nursing as caring: a model for transforming practice. New York: National League for Nursing, 1993.

2 BOYKIN, A. Ed. Living a care based program. New York: National League for Nursing, 1994.

3 GOFFMAN, I. Manicômios, prisões e conventos. São Paulo: Perspectiva, 1961.

4 LEININGER, M.M. Transcultural nursing: concepts, theories, and practices. New York: J ohn Wiley, 1978.

5 LEININGER, M.M. Caring: na essential human need. Thorofare: Slack, 1981.

6 NEVES-ARRUDA, A.E.; DIAS, L.P.M.; SILVA, A.L. Pesquisar para assistir. Rev. Esc. Enf. USP, São Paulo, v.26, n. esp. p. 119-124, out.1992.

7 MAYEROFF, R. On caring. New York: Harper \& Row, 1971.

8 PATRíclO, Z. Promovendo a cidadania através do conceito cuidado. Texto Contexto Enferm., Florianópolis, v.1, n.1, p.89-103, jan./fev. 1992.

9 PATRíCIO, Z. o processo de trabalho de enfermagem frente às novas concepções de saúde: repensando o cuidado/ propondo o cuidado (holístico). Texto Contexto Enferm., Florianópolis, v.2, n.1, p.67-82, jan./fev. 1993.

10 SHOTTON, L.; SEEDHOUSE, D. Practical dignity in caring. Nursing Ethics, v. 5, n.3, p.246-255, 1998.

11 SILVA, A.L. O processo de cuidar em enfermagem. Rev. Baiana de Enferm., Salvador, v.6, n.2, p.117-126, out. 1993.

12 WALDOW, V.R. Cuidado: uma revisão teórica. Rev. Gaúcha de Enferm., Porto Alegre, v.13, n.2, p.29-35, 1992.

13 WALDOW, V.R. Educação para o cuidado. Rev. Gaúcha de Enferm., Porto Alegre, v.14, n.2, p.108-112, jul. 1994.

14 WATSON, J. The philosophy and science of caring. Boston: Little Borwn, 1985.

Tereza Yoshiko Kakehashi Rua Brigadeiro Galvão 555 - ap. 74 - Barra Funda CEP 01151-000 - São Paulo - SP 